\title{
A Study about the Use of Co or Mn-Based Nanocatalysts for Styrene Epoxidation Reaction +
}

\author{
Lucía Rossi Fernández, Leandro Aguilar, Viviana Dorn and Gabriel Radivoy * \\ Instituto de Química del Sur (INQUISUR-CONICET), Departamento de Química, \\ Universidad Nacional del Sur, Av. Alem 1253, B8000CPB Bahía Blanca, Argentina; \\ lucia.rossi@uns.edu.ar (L.R.F.); leandrogaguilar@hotmail.com (L.A.); vdorn@uns.edu.ar (V.D.) \\ * Correspondence: gradivoy@criba.edu.ar \\ + Presented at the 24th International Electronic Conference on Synthetic Organic Chemistry, \\ 15 November-15 December 2020; Available online: https://ecsoc-24.sciforum.net/.
}

Received: date; Accepted: date; Published: date

\begin{abstract}
A new catalytic system consisting in $\mathrm{Mn}$ or $\mathrm{Co}$ nanoparticles supported on different materials (celite, zeolite, activated carbon, $\mathrm{CeO}_{2}, \mathrm{ZnO}, \mathrm{MgO}, \mathrm{Nb}_{2} \mathrm{O}_{5}$ ) have been studied for styrene epoxidation. The catalysts were prepared easily from commercially available starting materials. Reaction conditions were optimized by testing different solvents, reaction temperatures, oxidizing agents and optimal catalyst loading. CoNPs/MgO and TBHP as co-oxidant, in refluxing ACN, allowed total conversion to the epoxide with excellent yield and high selectivity.
\end{abstract}

Keywords: Styrene epoxidation; Mn and Co nanocatalysts; TBHP

\section{Introduction}

Epoxides are very useful synthetic intermediates as they can be easily converted into a wide variety of products through different chemical transformations on the reactive oxirane ring [1]. Despite many methodologies for the synthesis of epoxides have been reported [2], efficient and selective epoxidation of olefins remains a challenge. Currently, research is focused on easy-to-use and environmentally friendly oxidants such as $\mathrm{O}_{2}$, TBHP, air or $\mathrm{H}_{2} \mathrm{O}_{2}$, together with a transition metal catalyst that helps to improve the reactivity and selectivity of the oxygen transfer process [3]. In this work, Mn- or Co-based nanocatalysts have been studied for styrene epoxidation. These earth-abundant and low-cost metals are known to be part of biologically relevant complexes, such as porphyrins with a pivotal role in oxidation reactions [4,5]. Co or Mn nanoparticles (NPs) were synthesized by fast reduction of the corresponding metal chlorides, with an excess of Li sand and a catalytic amount of an arene as electron carrier [6]. The metal NPs thus obtained were immobilized on different materials: celite, zeolite, activated carbon, $\mathrm{CeO}_{2}, \mathrm{ZnO}, \mathrm{MgO}$ and $\mathrm{Nb}_{2} \mathrm{O}_{5}$. Reaction conditions were optimized by testing different solvents $\left(\mathrm{CH}_{2} \mathrm{Cl}_{2}, \mathrm{DMF}\right.$ and $\left.\mathrm{ACN}\right)$, reaction temperatures, oxidizing agents $\left(\mathrm{O}_{2}, \mathrm{H}_{2} \mathrm{O}_{2}\right.$ and TBHP) and optimal catalyst loading. The progress of the reaction was controlled by CG-MS. The use of CoNPs/MgO as the catalyst and TBHP as cooxidant, in refluxing ACN, allowed total conversion with high selectivity to the corresponding styrene oxide, after $24 \mathrm{~h}$ of reaction time.

\section{Methods}

\subsection{General Methods}

Anhydrous tetrahydrofuran was freshly distilled from sodium/benzophenone ketyl. Other solvents were treated before use by standard methods. All starting materials were of the best 
available grade (Aldrich, Fluka, Merck) and were used without further purification. Commercially available cobalt (II) chloride and manganese (II) chloride were oven-dried and then with a heat gun and vacuum before use. Reactions were monitored by thin-layer chromatography on silica gel plates (60F-254) visualized under UV light and/or using 5\% phosphomolybdic acid in ethanol and by CG-MS.

\subsection{Synthesis of Catalysts}

A mixture of lithium powder $(3.0 \mathrm{mmol})$ and DTBB $(0.1 \mathrm{mmol})$ in THF was stirred at room temperature under nitrogen atmosphere. When the reaction mixture turned dark green, indicating the formation of the corresponding lithium arenide, anhydrous cobalt or manganese chloride was added $(1 \mathrm{mmol})$. The resulting suspension was stirred until it turned black, indicating the formation of MNPs. After that, it was diluted with THF and support was added. The resulting suspension was stirred for $1 \mathrm{~h}$, and then bidistilled water was added for eliminating the excess of lithium. The resulting solid was filtered under vacuum in a Buchner funnel and washed successively with water and acetone. Finally, the solid was dried under vacuum (5 Torr).

\subsection{Styrene Epoxidation}

\section{Method A [7]: $\mathrm{H}_{2} \mathrm{O}_{2} / \mathrm{NaHCO}_{3}$}

In a Schlenk flask, the MnNPs/celite and $0.3 \mathrm{mmol}$ of styrene in DMF were shaken vigorously for 10 min at $0{ }^{\circ} \mathrm{C} .1 \mathrm{~mL}$ of $\mathrm{NaHCO}_{3}$ solution and $130 \mu \mathrm{L}$ of $\mathrm{H}_{2} \mathrm{O}_{2}$ were shaken in a flask for $10 \mathrm{~min}$ at $0{ }^{\circ} \mathrm{C}$. This solution was dripped into the Schlenk. The reaction mixture was stirred at working temperature. The catalyst was separated from the reaction mixture by filtration.

\section{Method B [8]: $\mathrm{O}_{2}$}

In a Schlenk flask, the MnNPs/celite was vigorously stirred in $\mathrm{DMF}$ or $\mathrm{CH}_{2} \mathrm{Cl}_{2}$. The reaction flask was purged and filled with oxygen with a balloon. Then $0.3 \mathrm{mmol}$ of styrene was added with a syringe. The reaction mixture was stirred at working temperature. The catalyst was separated from the reaction mixture by filtration.

\section{Method C [9]: TBHP}

In a sealed flask, Co or Mn-based nanocatalysts and $1 \mathrm{~mL}$ of $\mathrm{ACN}$ were vigorously stirred. Then $0.3 \mathrm{mmol}$ of styrene was added. Finally, $0.3 \mathrm{mmol}$ of TBHP solution was slowly added and the sealed reaction flask was immersed in an oil bath at working temperature. The catalyst was separated from the reaction mixture by filtration.

\section{Results and Discussion}

To study the styrene epoxidation reaction (Scheme 1), as can be seen from Table 1, we started using $75 \mathrm{mg}$ of MnNPs/celite as model catalyst and different oxidants, solvents, and temperatures. A very low conversion to styrene oxide $(7 \%)$ was achieved, using TBHP as the oxidant, in ACN at $60{ }^{\circ} \mathrm{C}$ and a similar amount of benzaldehyde was also observed, as another oxidation by-product (Table 1-entry 7).

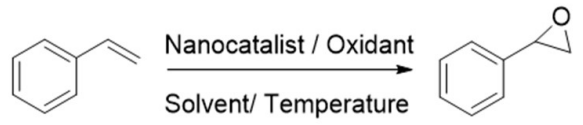

Scheme 1. styrene epoxidation reaction. 
Table 1. Optimization of reaction conditions *.

\begin{tabular}{ccccccc}
\hline Entry & Oxidant & Solvent & Temp & Styrene & Styrene Oxide & Benzaldehyde \\
\hline $\mathbf{1}$ & $\mathrm{H}_{2} \mathrm{O}_{2} / \mathrm{NaHCO}_{3}$ & $\mathrm{DMF}$ & $0{ }^{\circ} \mathrm{C}$ & $100 \%$ & - & - \\
$\mathbf{2}$ & $\mathrm{H}_{2} \mathrm{O}_{2} / \mathrm{NaHCO}_{3}$ & $\mathrm{DMF}$ & $\mathrm{RT}$ & $100 \%$ & - & - \\
$\mathbf{3}$ & $\mathrm{O}_{2}$ & $\mathrm{CH}_{2} \mathrm{Cl}_{2}$ & $0{ }^{\circ} \mathrm{C}$ & $100 \%$ & - & - \\
$\mathbf{4}$ & $\mathrm{O}_{2}$ & $\mathrm{DMF}$ & $0{ }^{\circ} \mathrm{C}$ & $100 \%$ & - & - \\
$\mathbf{5}$ & $\mathrm{O}_{2}$ & $\mathrm{DMF}$ & $\mathrm{RT}$ & $100 \%$ & - & - \\
$\mathbf{6}$ & $\mathrm{TBHP}$ & $\mathrm{ACN}$ & $\mathrm{RT}$ & $100 \%$ & - & - \\
$\mathbf{7}$ & $\mathrm{TBHP}$ & $\mathrm{ACN}$ & $60{ }^{\circ} \mathrm{C}$ & $88 \%$ & $7 \%$ & $5 \%$ \\
$\mathbf{8}$ & $\mathrm{TBHP}$ & $\mathrm{ACN} / \mathrm{DMF}(9: 1)$ & $60{ }^{\circ} \mathrm{C}$ & $100 \%$ & - & - \\
\hline \multicolumn{7}{c}{ Time: $24 \mathrm{~h}-\mathrm{MnNPs} / \mathrm{Melite} 75 \mathrm{mg}}$.
\end{tabular}

Based on this result, the reaction was tested in a sealed tube, using TBHP as oxidant, under reflux of $\mathrm{ACN}\left(82{ }^{\circ} \mathrm{C}\right)$, for $24 \mathrm{~h}$ improving the conversion to the epoxide $(26 \%)$, although the benzaldehyde formation also was increased (Table 2-entry 1A). As can be seen from entry 1B, 2B and $3 \mathrm{~B}$, longer reaction time not improved the conversion to the epoxide. Others MnNPs catalysts were evaluated, using ceria and zeolite as supports, although it was not possible to increase the conversion to the epoxide (entries 2 and 3 ).

Table 2. Study of different MnNPs nanocatalysts *

\begin{tabular}{cccccc}
\hline Entry & Time & Nanocatalyst & Styrene & Styrene Oxide & Benzaldehyde \\
\hline 1A & $24 \mathrm{~h}$ & MnNPs/celite $75 \mathrm{mg}$ & $48 \%$ & $26 \%$ & $26 \%$ \\
1B & $48 \mathrm{~h}$ & & $46 \%$ & $27 \%$ & $28 \%$ \\
2A & $24 \mathrm{~h}$ & MnNPs/ceria 75 mg & $50 \%$ & $22 \%$ & $28 \%$ \\
2B & $48 \mathrm{~h}$ & & $51 \%$ & $21 \%$ & $28 \%$ \\
3A & $24 \mathrm{~h}$ & MnNPs/zeolite 75 mg & $63 \%$ & $3 \%$ & $33 \%$ \\
3B & & & & \\
\hline
\end{tabular}

* TBHP/reflux ACN.

Then, the effective amount of MnNPs/celite catalyst required was evaluated, and the better result was obtaining with $20 \mathrm{mg}$ of the catalyst, yielding $43 \%$ of the epoxide and only $18 \%$ of benzaldehyde (Table 3 - entry 4 ).

Table 3. Effective amount of MnNPs/celite nanocatalyst *

\begin{tabular}{ccccc}
\hline Entry & Amount of MnNPs/Celite & Styrene & Styrene Oxide & Benzaldehyde \\
\hline $\mathbf{1}$ & $100 \mathrm{mg}$ & $76 \%$ & $11 \%$ & $13 \%$ \\
$\mathbf{2}$ & $75 \mathrm{mg}$ & $48 \%$ & $26 \%$ & $26 \%$ \\
$\mathbf{3}$ & $50 \mathrm{mg}$ & $57 \%$ & $23 \%$ & $20 \%$ \\
$\mathbf{4}$ & & & \\
\hline \multicolumn{5}{c}{ * TBHP/reflux ACN/Time: $24 \mathrm{~h}}$.
\end{tabular}

Based on the results already reported, that we mentioned above, we decided to test the reaction with cobalt as metal of the nanocatalyst. As can be seen from Table 4, the reaction was carried out using $20 \mathrm{mg}$ of the CoNPs on different supports, with TBHP as oxidant, under reflux of $\mathrm{ACN}\left(82{ }^{\circ} \mathrm{C}\right)$, for $24 \mathrm{~h}$ and $48 \mathrm{~h}$.

In all cases, the reaction at $24 \mathrm{~h}$ (entries A) gave better or very similar conversions to the epoxide than the reactions at $48 \mathrm{~h}$ (entries B).

The reaction with $20 \mathrm{mg}$ of CoNPs/celite at $24 \mathrm{~h}$ (Table 4-entry 1A) give a major conversion of epoxide (65\%) than the same reaction using MnNPs/celite as nanocatalyst $(43 \%)$, and almost the same amount of the oxidation by-product (Table 3-entry 4). Similar results were obtained when we employed CoNPs/zeolite as nanocatalysts (entry 3). Among all the nanocatalysts evaluated, the 
best conversion to the epoxide (67\%) was obtained with $20 \mathrm{mg}$ of the CoNPs/MgO nanocatalyst (entry 6).

Table 4. Study of different CoNPs nanocatalysts *.

\begin{tabular}{cccccc}
\hline Entry & Time & Nanocatalyst & Styrene & Styrene Oxide & Benzaldehyde \\
\hline 1A & $24 \mathrm{~h}$ & CoNPs/celite & $12 \%$ & $65 \%$ & $23 \%$ \\
1B & $48 \mathrm{~h}$ & & $34 \%$ & $46 \%$ & $20 \%$ \\
2A & $24 \mathrm{~h}$ & CoNPs/ceria & $67 \%$ & $17 \%$ & $16 \%$ \\
2B & $48 \mathrm{~h}$ & & $57 \%$ & $24 \%$ & $19 \%$ \\
3A & $24 \mathrm{~h}$ & CoNPs/zeolite & $11 \%$ & $62 \%$ & $27 \%$ \\
3B & $48 \mathrm{~h}$ & & $7 \%$ & $66 \%$ & $27 \%$ \\
4A & $24 \mathrm{~h}$ & CoNPs/C & $73 \%$ & $12 \%$ & $15 \%$ \\
4B & $48 \mathrm{~h}$ & & $75 \%$ & $10 \%$ & $15 \%$ \\
5A & $24 \mathrm{~h}$ & CoNPs/ZnO & $26 \%$ & $33 \%$ & $41 \%$ \\
5B & $48 \mathrm{~h}$ & & $21 \%$ & $31 \%$ & $48 \%$ \\
6A & $24 \mathrm{~h}$ & CoNPs/MgO & $4 \%$ & $67 \%$ & $29 \%$ \\
6B & $48 \mathrm{~h}$ & & $3 \%$ & $72 \%$ & $25 \%$ \\
\hline
\end{tabular}

* TBHP/reflux ACN/20 mg of the nanocatalyst.

Then, the effective amount of CoNPs/MgO catalyst required was evaluated, and the best results were obtained with $10 \mathrm{mg}$ of the CoNPs/MgO catalyst, with total conversion, giving 91\% yield of styrene oxide and only $9 \%$ yield of benzaldehyde at $24 \mathrm{~h}$, showing an excellent selectivity (Table 5-entry 2). The reaction was also tested with $5 \mathrm{mg}$ of nanocatalyst, and total conversion was obtained after $48 \mathrm{~h}$, but with $76 \%$ yield of styrene oxide and $24 \%$ yield of benzaldehyde (Table $5-$ entry 3B).

Table 5. Effective amount of CoNPs/MgO nanocatalyst *.

\begin{tabular}{cccccc}
\hline Entry & Time & Nanocatalyst & Styrene & Styrene Oxide & Benzaldehyde \\
\hline 1A & $24 \mathrm{~h}$ & CoNPs/MgO $20 \mathrm{mg}$ & $4 \%$ & $67 \%$ & $29 \%$ \\
1B & $48 \mathrm{~h}$ & & $3 \%$ & $71 \%$ & $26 \%$ \\
2A & $24 \mathrm{~h}$ & CoNPs/MgO $10 \mathrm{mg}$ & - & $91 \%$ & $9 \%$ \\
2B & $48 \mathrm{~h}$ & & - & $95 \%$ & $5 \%$ \\
3A & $24 \mathrm{~h}$ & CoNPs/MgO $5 \mathrm{mg}$ & $10 \%$ & $59 \%$ & $31 \%$ \\
3B & $48 \mathrm{~h}$ & & - & $76 \%$ & $24 \%$ \\
\hline
\end{tabular}

* TBHP/reflux ACN.

Taking into consideration the excellent results obtained using $10 \mathrm{mg}$ of the $\mathrm{CoNPs} / \mathrm{MgO}$ nanocatalyst, the same conditions were used to evaluate other cobalt and manganese nanocatalysts. When the reaction was carried out with $10 \mathrm{mg}$ of CoNPs/celite, improved the conversion to the styrene oxide respect to the same reaction using $20 \mathrm{mg}$ of nanocatalyst $(74 \%$ and $65 \%$ respectively, Table 6-entry 1 and Table 4-entry 1). The CoNPs/zeolite nanocatalyst was also evaluated, although the performance of the epoxidation did not improve compared to the same reaction utilized $20 \mathrm{mg}$ of nanocatalyst $(56 \%$ and $62 \%$ of the epoxide respectively, Table 6 - entry 2 and Table 4-entry 3). Considering the excellent performance of the $\mathrm{MgO}$ as support, also, the MnNPs/MgO nanocatalyst was tested, giving $66 \%$ of styrene oxide and $31 \%$ of benzaldehyde after $48 \mathrm{~h}$ (Table 6-entry 3B). This result was better than obtained using MnNPs/celite (43\% of epoxide), but not enough to exceed that achieved with the cobalt nanocatalyst. Bearing in mind that niobium oxide has interesting oxide-reducing properties, we evaluated the reaction using $10 \mathrm{mg}$ of $\mathrm{CoNPs} / \mathrm{Nb}_{2} \mathrm{O}_{5}$ as nanocatalyst (Table 6-entry 4). The conversion was similar to obtained with 10 mg of CoNPs/celite, but could not be better than the conversion achieved by the CoNPs/MgO nanocatalyst. 
Table 6. Study of different Co- and MnNPs catalysts *.

\begin{tabular}{|c|c|c|c|c|c|}
\hline Entry & Time & Nanocatalyst & Styrene & Styrene Oxide & Benzaldehyde \\
\hline 1A & $24 \mathrm{~h}$ & CoNPs/celite & $8 \%$ & $74 \%$ & $18 \%$ \\
\hline 1B & $48 \mathrm{~h}$ & & $3 \%$ & $79 \%$ & $18 \%$ \\
\hline $2 \mathrm{~A}$ & $24 \mathrm{~h}$ & CoNPs/zeolite & $16 \%$ & $56 \%$ & $28 \%$ \\
\hline 2B & $48 \mathrm{~h}$ & & $10 \%$ & $63 \%$ & $27 \%$ \\
\hline $3 A$ & $24 \mathrm{~h}$ & MnNPs/MgO & $20 \%$ & $47 \%$ & $33 \%$ \\
\hline 3B & $48 \mathrm{~h}$ & & $3 \%$ & $66 \%$ & $31 \%$ \\
\hline $4 \mathrm{~A}$ & $24 \mathrm{~h}$ & $\mathrm{CoNPs} / \mathrm{Nb}_{2} \mathrm{O}_{5}$ & $3 \%$ & $73 \%$ & $24 \%$ \\
\hline $4 B$ & $48 \mathrm{~h}$ & & $2 \%$ & $72 \%$ & $26 \%$ \\
\hline
\end{tabular}

${ }^{*} \mathrm{TBHP} /$ reflux ACN/10 mg of the nanocatalyst.

Considering that there is evidence in the literature about a radical mechanism for the epoxidation by metal catalysis $[10,11]$, as can be seen from Table 7 , we carried out a series of reactions to confirm that. Initially, the reaction was performed using $10 \mathrm{mg}$ of CoNPs/MgO and TBHP under reflux of ACN for $8 \mathrm{~h}$ yielding $64 \%$ of the epoxide and $24 \%$ of benzaldehyde (entry 1 ). In the absence of the nanocatalyst, only $33 \%$ of the epoxide was obtained (entry 2). Also, the reaction was tested without TBHP, with fully recovering the starting styrene (entry 3). And finally, the reaction was carried out in the presence of hydroquinone, a known radical scavenger, and the epoxide formation was inhibited almost completely (entry 4). All these results, could confirm the presence of a radical mechanism for this epoxidation reaction.

Table 7. Mechanistic study of the epoxidation reaction.

\begin{tabular}{ccccccc}
\hline Entry & Nanocatalyst & Additive & Oxidant & Styrene & Styrene Oxide & Benzaldehyde \\
\hline $\mathbf{1}$ & CoNPs/MgO 10 mg & - & TBHP & $12 \%$ & $64 \%$ & $24 \%$ \\
$\mathbf{2}$ & - & - & TBHP & $53 \%$ & $33 \%$ & $14 \%$ \\
$\mathbf{3}$ & CoNPs/MgO 10 mg & - & - & $100 \%$ & - & - \\
$\mathbf{4}$ & CoNPs/MgO 10 mg & Hidroquinone & TBHP & $78 \%$ & $9 \%$ & $13 \%$ \\
\hline
\end{tabular}

* reflux ACN/Time: $8 \mathrm{~h}$.

\section{Conclusions}

A simple methodology has been developed for the synthesis of metallic nanocatalysts based on Co or Mn nanoparticles (NPs), which were synthesized by fast reduction of the corresponding metal chlorides, with an excess of Li sand and a catalytic amount of an arene as electron carrier. The metal NPs thus obtained were immobilized on different supports. Reaction conditions were optimized by testing different solvents, reaction temperatures, oxidizing agents, and optimal catalyst loading. Based on the reported study, the use of $10 \mathrm{mg}$ of CoNPs/MgO, as nanocatalyst, and TBHP, as co-oxidant, under reflux of ACN, allowed the total conversion with high selectivity to the corresponding styrene oxide, after $24 \mathrm{~h}$ of the reaction time. We are studying the scope of this method for the epoxidation of alkenes with a structural variety, as well as the possibility of recovery and reuse of the nanocatalyst.

Acknowledgments: This work was generously supported by the Consejo Nacional de Investigaciones Científicas y Técnicas (CONICET, PIP-2011-11220100100268), Agencia Nacional de Promoción Científica y Tecnológica (ANPCyT, Prest. BID, PICT-2014-2171) and Universidad Nacional del Sur (UNS, PGI 24/Q072) from Argentina. L.R. thanks the CONICET for a doctoral fellowship.

\section{References}

1. Jorgensen, K.A. Chem. Rev. 1989, 89, 431-458.

2. Zhu, Y.; Wang, Q.; Cornwall, R.G.; Shi, Y. Chem. Rev. 2014, 114, 8199-8256.

3. Kazemnejadi, M.; Mahmoudi, B.; Sharafi, Z.; Nasseri, M.A.; Allahresani, A.; Esmaeilpour, M.J. Org. Chem. 2019, 896, 59-69. 
4. Yudin, A.K. Aziridines and Epoxides in Organic Synthesis; Wiley-VCH: 2006; pp. 185-228.

5. Jorgensen, K.A. Chem. Rev. 1989, 89, 431-458.

6. Nador, F.; Volpe, M.A.; Alonso, F.; Feldhoff, A.; Kirschning, A.; Radivoy, G. Appl. Catal. A Gen. 2013, 455, $39-45$.

7. Qi, B.; Lou, L.-L.; Yu, K.; Bian, W.; Liu, S. Catal. Comm. 2011, 15, 52-55.

8. Buxaderas, E.; Graziano Mayer, M.; Volpe, M.A.; Radivoy, G. Synthesis 2017, 49, 1387-1393.

9. Zhang, Q.; Wang, Y.; Itsuki, S.; Shishido, T.; Takehira, K. J. Mol. Catal. A Chem. 2002, 188, 189-200.

10. Ghosh, B.K.; Moitra, D.; Chandel, M.; Patra, M.K.; Vadera, S.R.; Ghosh, N.N. Catal. Lett. 2017, 147, 10611076.

11. Kazemnejadi, M.; Mahmoudi, B.; Sharafi, Z.; Nasseri, M.A.; Allahresani, A.; Esmaeilpour, M.J. Orgznomet. Chem. 2019, 896, 59-69.

Publisher's Note: MDPI stays neutral with regard to jurisdictional claims in published maps and institutional affiliations.

(C) 2020 by the authors. Submitted for possible open access publication under the terms and conditions of the Creative Commons Attribution (CC BY) license (http://creativecommons.org/licenses/by/4.0/). 